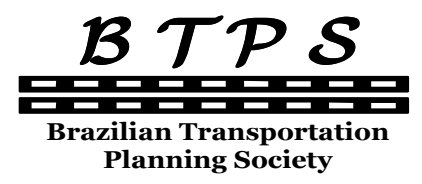
Journal of Transport Literature
Vol. 8, n. 2, pp. 201-220, Apr. 2014
Research Directory

JTL|RELIT

www.transport-literature.org ISSN 2238-1031

\title{
Monitoring the condition of roads pavement surfaces: proposal of methodology using hyperspectral images
}

[Monitoramento das condições das superfícies de pavimentos rodoviários: proposta de metodologia utilizando imagens hiperespectrais]

\author{
Marcos Ribeiro Resende, Liedi Legi Bariani Bernucci, José Alberto Quintanilha* \\ ATECH - Fundação para Tecnologias Críticas - Brazil, University of São Paulo - Brazil, University of São Paulo - Brazil
}

Submitted 29 Nov 2012; received in revised form 26 Feb 2013; accepted 27 Apr 2013

\begin{abstract}
With the current system of concession roads in Brazil, both concessionaires and regulatory agents have been charged with improving the quality of the pavement on Brazilian highways. This situation requires the search for new tools that can facilitate the survey of pavement conditions in less time and at a lower cost than traditional methods. Recently, an increasing number of high-resolution spatial images have become available on the world market following the development of new remote sensing satellites and airborne sensors. Similarly, multispectral images and even hyperspectral images are now available commercially and for scientific research. The paper presents a new methodology for the identification of asphalted pavement surfaces condition and the classification of the main types of asphalt defects using hyperspectral images from airborne digital sensors. The objective of this study was to generate indexes of pavement conditions from images that can be compared with the indicators of pavement surface conditions already used by national regulatory agencies.
\end{abstract}

Key words: pavements, remote sensing, asphalt, hyperspectral, classification.

\section{Resumo}

No atual sistema de concessões rodoviária do Brasil ambos, concessionárias e agências reguladoras têm a missão de melhorar a qualidade dos pavimentos rodoviários no País. Tal situação requer a pesquisa e a identificação de novas ferramentas que facilitem o levantamento das condições dos pavimentos rodoviários num tempo e custos menores que os métodos usuais. Recentemente, se verificou um grande aumento da disponibilidade de imagens de sensoriamento remoto com alta resolução espacial, seguindo uma tendência do mercado de novos satélites de sensoriamento remoto, e de sensores aerotransportados. De forma similar, imagens multi e hiperespectrais estão disponíveis tanto comercialmente quanto para a pesquisa científica. 0 artigo apresenta uma nova metodologia para a identificação das condições do asfalto em superfícies pavimentadas e uma classificação dos tipos de defeitos identificáveis a partir de imagens hiperespectrais adquiridas por sensores aerotransportados. O objetivo do artigo é o de mostrar que índices das condições das superfícies dos pavimentos asfaltados gerados via imagens hiperespectrais podem ser comparados com os indicadores vigentes, utilizados pela agência reguladora nacional.

Palavras-Chave: pavimentos, sensoriamento remoto, asfalto, hiperspectral, classificação.

*Email: jaquinta@usp.br.

\section{Recommended Citation}

Resende, M. R., Bernucci, L. L. B. and Quintanilha, J. A. (2014) Monitoring the condition of roads pavement surfaces: proposal of methodology using hyperspectral images. Journal of Transport Literature, vol. 8, n. 2, pp. 201-220.

- JTL/RELIT is a fully electronic, peer-reviewed, open access, international journal focused on emerging transport markets and published by BPTS - Brazilian Transport Planning Society. Website www.transport-literature.org. ISSN 2238-1031. 


\section{Introduction}

This study's main objective was to investigate the use of digital images with high spatial and spectral resolutions for monitoring the conditions of asphalted pavement surfaces. The approach implemented was to analyze which defects on the asphalted pavement surfaces could be detected by the set of images available for study and to generate quality indexes for asphalt surfaces that can be compared with the standardized indexes used by the national regulatory agencies.

With the current system of concession roads in the country, both concessionaires and regulatory agents have been charged with improving the quality of the pavement on Brazilian roads. This need requires the search for new tools to enable and facilitate the surveillance of pavement conditions in less time and at a lower cost than traditional methods.

According to the Annual Statistics of Land Transport (2008) provided by the Agência Nacional de Transportes Terrestres (ANTT), Brazil contains 211,678 km of paved highways throughout all of its territories, including 61,304 km of federal highways, 17,056 km of coincident state highways, $106,548 \mathrm{~km}$ of state highways, and $26,770 \mathrm{~km}$ of municipal highways.

According to the National Transportation Council (CNT) highway study (2009), regarding "the survey completed by the study of $89,552 \mathrm{~km}$ of the national highway network, the condition of the bearing surface is, predominantly, totally perfect on $43.4 \%(38,870 \mathrm{~km})$ of pavements. Signs of wear are evident on $33.1 \%$ of pavements, and defects are present on $23.5 \%$, mainly as cracks and/or patches (17.8\%), and sags, undulations, and holes (4.6\%). The critical situation of totally destroyed pavement is evident in $1.1 \%$ of pavements, equal to 960 $\mathrm{km} "$.

"The usefulness of the pavement value diminishes with the passing of time due to two main factors: traffic and weather" (Bernucci et al., 2008). According to Herold and Roberts (2005), the cost of conducting extensive inspections is high and many cities only inspect the main highways, while the secondary highways are neglected or rarely inspected. 
A set of technologies is already in use for the monitoring of the surface conditions of asphalted pavements, such as those used on highway inspection vehicles: video recording and analysis, digital images, and longitudinal laser profiling. According to Herold and Roberts (2005), recent advances in image spectrometry have allowed precise identification of the physical and chemical properties of the materials using imaging techniques.

Daily remote sensing images are rich sources of information for the user, especially because of their spatial, spectral, and temporal resolutions as well as the texture and precision offered. With improvements in remote sensing image quality, the difficulty of dealing with a substantial volume of data to obtain the information of interest has also increased. "The higher resolutions demand a new type of processing that goes beyond observation of individual pixels" (Blaschke et al., 2005).

"Therefore, a new vision has arisen for image processing, object-based data processing. Instead of individually classifying pixels by their spectral characteristics, the new procedures involve outlining homogeneous objects as the basis for subsequent processing" (Blaschke and Kux, 2005).

A detailed description of the methodology developed for the automatic extraction of the asphalted roads from hyperspectral images using a hybrid pixel-by-pixel and object-based classification is given in Resende et al. (2012).

\section{Previous works}

The National Center for Remote Sensing in Transportation (NCRST) of the California University (Santa Bárbara), is using spectral images to map urban features and roads infrastructure. They use images from the Airborne Visible/Infrared Imaging Spectrometer (AVIRIS) sensors to determine the age and conditions of the pavements (Herold et al., 2008).

In Brazil, Resende et al. (2008) and Ferreira and Vieira (2009a and 2009b) developed experiments using high spatial resolution images to detect defects in asphalted paved surfaces.

According Wang and Smadi (2011), futures implementations of a 3D laser system could be the best solution to automatically process to detect defects in paved surfaces. This procedures 
and its classification are not completely automatized yet. Another successful way to get information about the pavement conditions is using sensors portable by drones.

One similar subject founded in the academic literature related to the applications discussed in this paper is the use of remote sensing techniques in impervious surface. According to Weng (2012), "a literature search via Scopus, the largest abstract and citation database of peerreviewed literature, indicates that in the 1990s the number of publications on remote sensing of impervious surface was limited. ..., at the turn of the 21 st century, remote sensing of impervious surfaces was rapidly gaining interest in the remote sensing community and the annual publications and citations on the subject increased exponentially."

A directly related literature about the subjects mentioned in this paper is the article published by Proto et al (2010). They describe the ISTIMES project, were the monitoring of transport infrastructures will be carried out at highest possible spatial resolution via the use of advanced multidimensional imaging techniques.

\section{Database}

The data set used in the study comprised four images from the CASI-1500 sensor acquired by the Low Cost Air Monitoring System - LCAMS (Rodrigues et al., 2007), on February 3, 2010. Two images contained 24 continuous spectral bands from $380.1 \mathrm{~nm}$ to $1,033.1 \mathrm{~nm}$, with a spatial resolution of $50 \mathrm{~cm}$ per pixel and a radiometric resolution of 14 bits. The other two images contained 8 continuous spectral bands from $380.1 \mathrm{~nm}$ to $1,033.1 \mathrm{~nm}$, with a spatial resolution of $25 \mathrm{~cm}$ per pixel and a radiometric resolution of 14 bits. 
Table 1 - Description of the spectral bands of the images used in the study

\begin{tabular}{|c|c|c|c|c|}
\hline Band & $\begin{array}{c}\text { Image 01-I01 } \\
(\mathrm{nm})\end{array}$ & $\begin{array}{c}\text { Image 02-I02 } \\
(\mathrm{nm})\end{array}$ & $\begin{array}{c}\text { Image 03-I03 } \\
(\mathrm{nm})\end{array}$ & $\begin{array}{c}\text { Image 04-I04 } \\
(\mathrm{nm})\end{array}$ \\
\hline B01 & $380.1+/-14.1$ & $380.1+/-14.1$ & $408.4+/-42.4$ & $408.4+/-42.4$ \\
\hline B02 & $408.3+/-14.1$ & $408.3+/-14.1$ & $493.4+/-42.5$ & $493.4+/-42.5$ \\
\hline B03 & $436.7+/-14.2$ & $436.7+/-14.2$ & $578.5+/-42.6$ & $578.5+/-42.6$ \\
\hline B04 & $465.0+/-14.2$ & $465.0+/-14.2$ & $663.8+/-42.7$ & $663.8+/-42.7$ \\
\hline B05 & $493.3+/-14.2$ & $493.3+/-14.2$ & $749.1+/-42.7$ & $749.1+/-42.7$ \\
\hline B06 & $521.7+/-14.2$ & $521.7+/-14.2$ & $834.5+/-42.6$ & $834.5+/-42.6$ \\
\hline B07 & $550.1+/-14.2$ & $550.1+/-14.2$ & $919.7+/-42.6$ & $919.7+/-42.6$ \\
\hline B08 & $578.5+/-14.2$ & $578.5+/-14.2$ & $1004.8+/-42.5$ & $1004.8+/-42.5$ \\
\hline B09 & $606.9+/-14.2$ & $606.9+/-14.2$ & & \\
\hline B10 & $635.4+/-14.2$ & $635.4+/-14.2$ & & \\
\hline B11 & $663.8+/-14.2$ & $663.8+/-14.2$ & & \\
\hline B12 & $692.3+/-14.2$ & $692.3+/-14.2$ & & \\
\hline B13 & $720.7+/-14.2$ & $720.7+/-14.2$ & & \\
\hline B14 & $749.1+/-14.2$ & $749.1+/-14.2$ & & \\
\hline B15 & $777.6+/-14.2$ & $777.6+/-14.2$ & & \\
\hline B16 & $806.0+/-14.2$ & $806.0+/-14.2$ & & \\
\hline B17 & $834.5+/-14.2$ & $834.5+/-14.2$ & & \\
\hline B18 & $862.9+/-14.2$ & $862.9+/-14.2$ & & \\
\hline B19 & $891.3+/-14.2$ & $891.3+/-14.2$ & & \\
\hline B20 & $919.7+/-14.2$ & $919.7+/-14.2$ & & \\
\hline B21 & $948.1+/-14.2$ & $948.1+/-14.2$ & & \\
\hline B22 & $976.4+/-14.2$ & $976.4+/-14.2$ & & \\
\hline B23 & $1004.8+/-14.2$ & $1004.8+/-14.2$ & & \\
\hline B24 & $1033.1+/-14.2$ & $1033.1+/-14.2$ & & \\
\hline & & & & \\
\hline
\end{tabular}

Images with multiple electromagnetic spectrum bands, such as the ones used ( 24 bands in the first two images and 8 in the latter two images), are called multispectral / hyperspectral images. These images are all high-spatial resolution images because they have a sub-metric spatial resolution.

The study area shown in Figure 1 is located in the urban area of the city of Sorocaba, transected by the Raposo Tavares Highway, SP-270, inside the polygon defined by the points

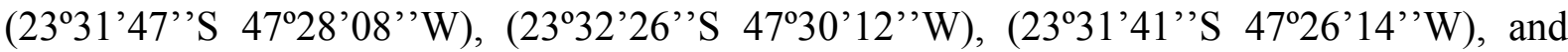
(2331'13's 47²6'28', W). 


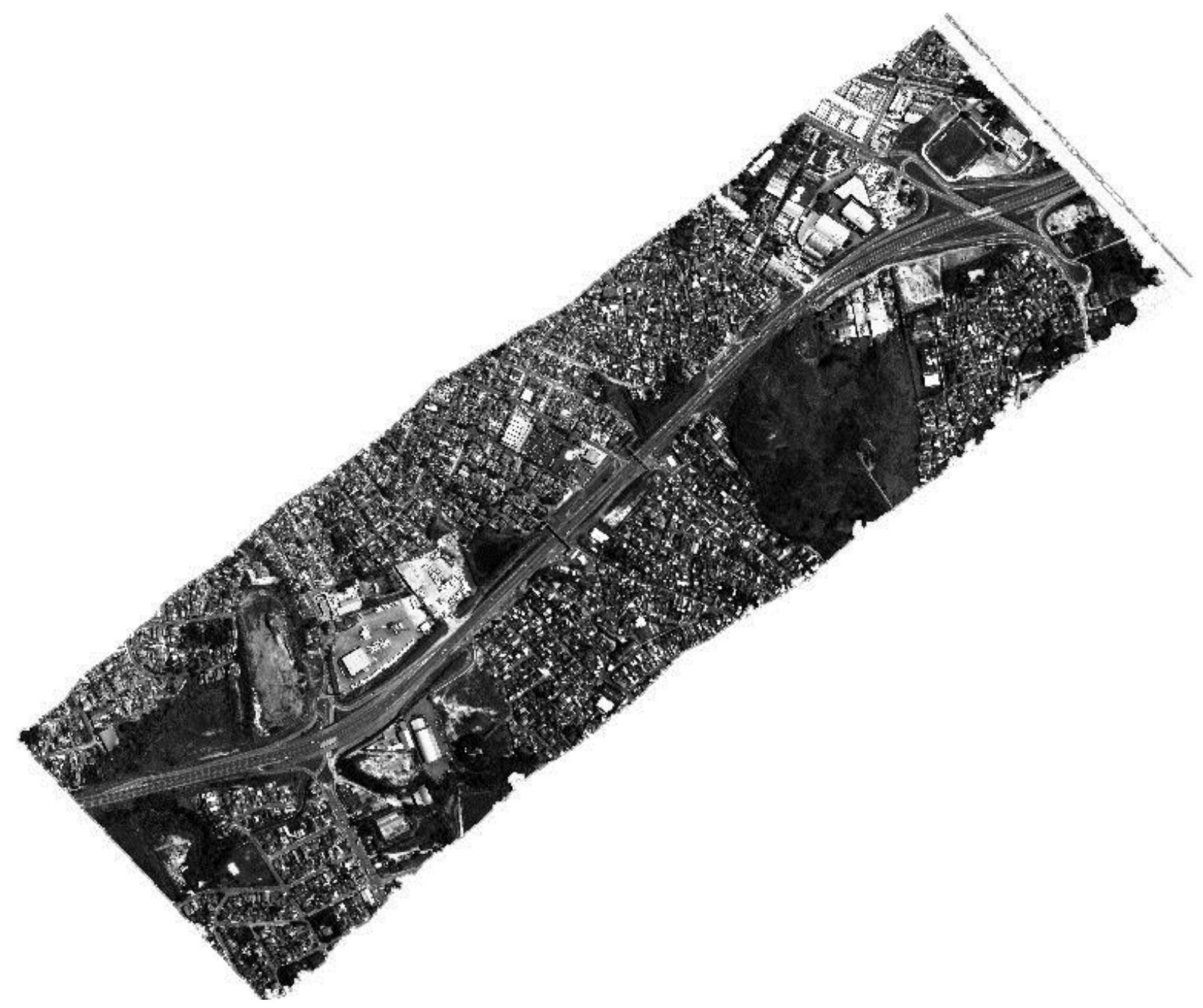

Figure 1 - Image I01, with 24 spectral bands and a $50 \mathrm{~cm}$ spatial resolution, of the Study Area, Sorocaba, São Paulo - SP (ATECH, 2010)

\section{Methodology}

The principal methods for the evaluation of the surface conditions of asphalted pavements and the current quality indexes were established by the DNIT 006/2003 - PRO and DNIT 008/2003 - PRO standards (DNIT - Departamento Nacional de Infra-estrutura de Transportes)

The DNIT 006/2003 - PRO standard establishes a method for systematically surveying pavement defects and scoring them based on the Global Severity Index (GSI), which can be used for reinforcement projects. The GSI is an indicator of pavement surface quality. It is obtained by summing the Individual Severity Index (ISI) that are calculated by multiplying 
the relative frequency of defect occurrences in the segments surveyed by a weighting factor for each observed defect. From the number calculated for the GSI, it is possible to award the pavement a grade that portrays the degree of degradation of the pavement surface: excellent, good, regular, bad, and terrible.

The DNIT 008/2003 - PRO standard establishes the conditions required in the evaluation of the surfaces of flexible and semi rigid pavements by Continuous Visual Survey (CVS) to determine the Flexible Pavement Condition Index (FPCI). This standard also provides the elements necessary for calculating the Expedite Global Severity Index (EGSI) and the State of the Pavement Surface Index (SPSI).

The EGSI is calculated be recording the frequency of the defects and their respective weights. The defects are grouped into three categories: cracks, deformations, and pans/patches.

The use of hyperspectral images with a high spatial resolution for monitoring the condition of asphalt pavement requires a set of processing steps and the appropriate input data to produce satisfactory results. The objective is to create quality indexes from a hyperspectral image that permits the assessment of the conditions of asphalted pavement surfaces. The methodology is based on two main processes: 1) asphalt detection and 2) asphalt defects classification.

To minimize the computational effort required for the study steps and to validate the methodology, areas of interest (AOI) were selected that were representative of the entire set of pavement conditions and contained information on pavement defects. The selection of the areas of interest was made by visual analysis with the objective of selecting significant areas that met the following criteria: urban areas, rural areas, areas with 8 spectral bands, areas with 24 spectral bands, areas with a spatial resolution of $25 \mathrm{~cm}$, areas with a spatial resolution of $50 \mathrm{~cm}$, areas with little noise or few image sensor artifacts, and areas with asphalt defects that were identified by field research.

\subsection{Asphalt Detection}

To allow for the identification and classification of asphalt defects, the first step is to distinguish the areas of asphalt in the original image. This step alone is already the subject of great effort within the field of remote sensing and image processing, especially when the images are of urban areas with great heterogeneity. 
The methodology shown in Figure 2 was proposed to improve the efficiency of the identification of asphalt in hyperspectral images with high-spatial resolution. This methodology combines the pixel classification technique, which considers the nature of the spectral response, with the object-based classification technique, which considers the spatial and morphological features of objects under analysis in addition to the spectral information. Further details of the object-based classification technique can be found in Nobrega et al. (2008). For details of the particular methodology used in this study, consult Resende et al. (2012).

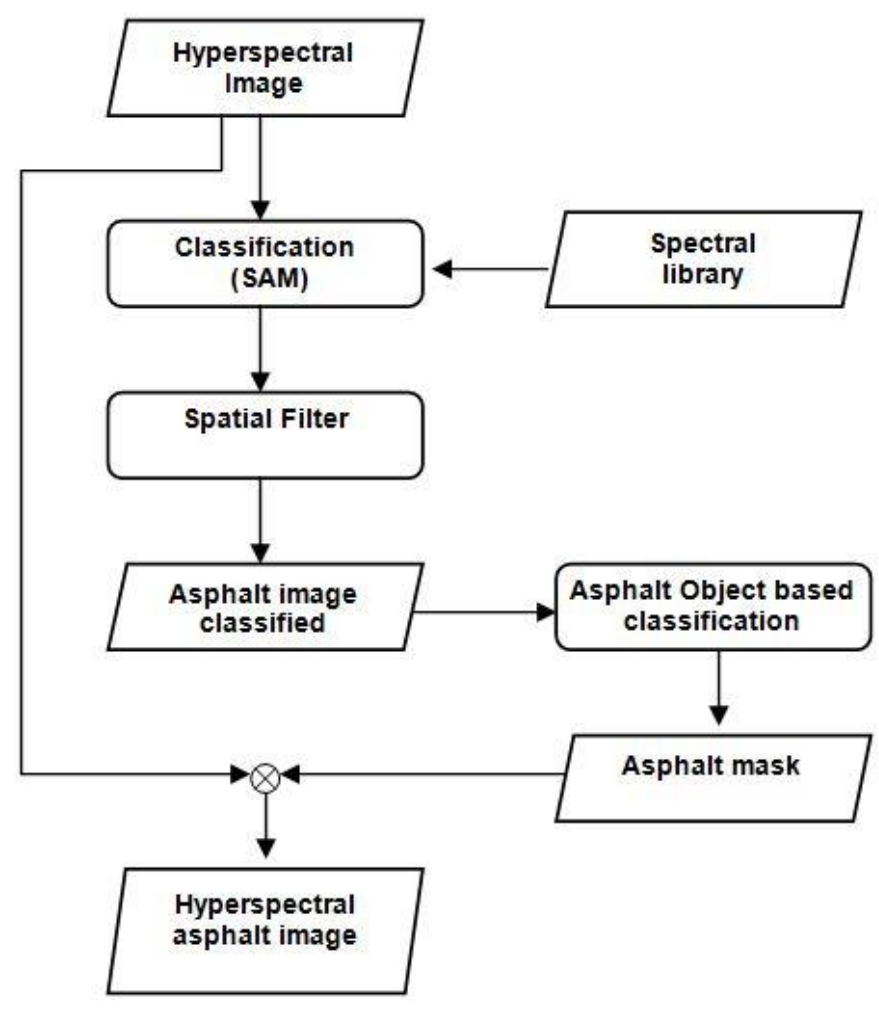

Figure 2 - Methodology for the detection and separation of the asphalt areas in the hyperspectral images

The Definiens Developer 7 software was used to complete the object-based classification in this study. Three classes were created: Asphalt, Non-Asphalt, and Asphalt Island. The Asphalt and the Non-Asphalt classes were defined by the spectral values of the object. The Asphalt Island class was defined by the neighborhood criteria. For an object to be considered an Asphalt Island, the object should belong to the Asphalt class and be surrounded by the NonAsphalt class. After classification, the objects in the Asphalt Island and the Non-Asphalt 
classes were discarded, leaving only the objects from the Asphalt class. The image was then transformed to generate a binary mask from the results of the object-based classification, as shown in Figure 3. This mask was applied to the original hyperspectral image to delineate and remove the asphalt regions from the original image. Figure 3 shows the final results of the classification for one part of the area studied: the Asphalt class is shown in dark gray and the Asphalt Island class is depicted in gray.

To evaluate the results of each processing step from the first phase of this methodology, true field images of the areas of interest (AOI) were manually obtained and visually constructed. By using the true field images, it was possible to evaluate whether the methodological steps implemented in fact improved the classification of asphalt from hyperspectral images.

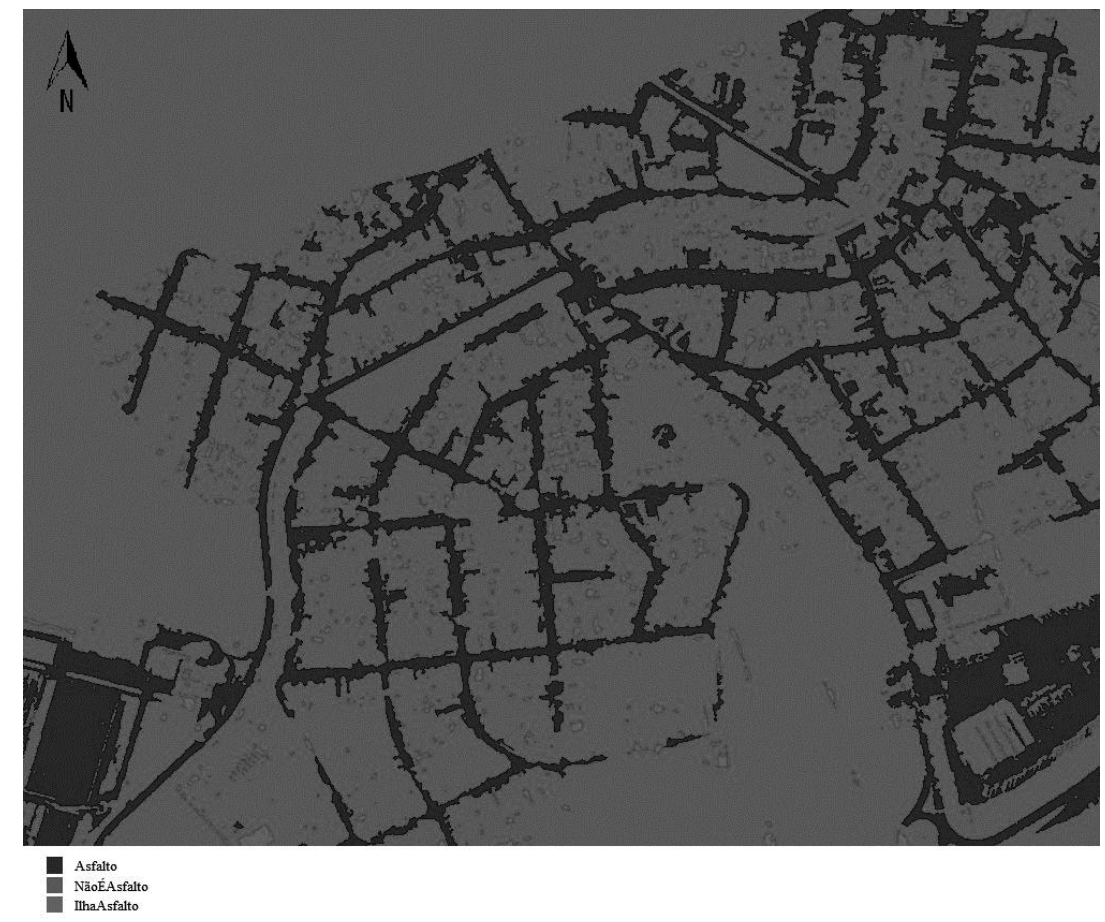

Figure 3 - Image with asphalt classifications resulting from the object-based classification algorithm (Asphalt=dark gray, Non-Asphalt=light gray and Asphalt Island=gray)

Four spatial filters were initially evaluated for their use in the methodology: the sieve filter, the clump filter, the average convolution filter, and the low-pass convolution filter. The order in which the filters are applied influences the final results of the image processing. To analyze the impact of the order and the effect produced by the filters, a decision tree experiment was 
completed. Each node on the tree represents a sequence of spatial filter application. A confusion matrix was calculated for each node of the decision tree, and the amount that each filter contributed to the classification of the asphalt image was measured.

\subsection{Classification of Asphalt Defects}

The classification stage is primarily based on the geometry of the objects, using the tools and measurements available in the software for the object-based analysis, with the intent of finding patterns that exist in the asphalt defects. The index of each defect category is calculated by summing the area of each defect in the classified object and dividing by the sum of the area of the object that is classified as asphalt for a determined region.

$$
I_{c a t}=\frac{\sum a ́ r e a\left(O_{c a t}\right)}{\sum a ́ r e a\left(O_{\text {asfalto }}\right)}
$$

where:

Icat: Defect analysis category index;

Ocat: Object classified as belonging to the defect category being analyzed;

Oasphalt: Object classified as asphalt.

Similarly to the calculations of the GSI or EGSI performed using the conventional methodology, a weighted sum of the Icat values is obtained from the images. Thus, in the end, we have a GSI' or EGSI' that has been calculated from the images and can be compared with the GSI or EGSI, respectively, calculated using the conventional methodology.

The principal defects that could be detected in the images available for the study were patches, holes, long longitudinal/transversal cracks, and alligator cracks.

To classify the asphalt patches in the images studied, a classification system was constructed that considers the spectral features and the form features of the objects. The following attributes were used in the patch classification: Edge Index, Length Width Ratio, Rectangular Fit, and the Form Index. Samples of patch objects were collected from the same image to construct pertinence functions for the class attributes. The values of the patch class attributes for the samples were used to scale the confidence intervals of the pertinence functions. 
The Long Crack class was defined from the following attributes: Area, Length Width Ratio, Form Index and the spectral values. The classification system was constructed based on the behavior of thin objects, which explains the use of the Length Width Ratio and the Form Index and also why the values are representative of small object areas. The Crack samples from the area of interest were used to construct the pertinence functions for the attributes selected for the Long Crack class.

\section{Field research}

To confirm the presence of the problems identified in the images, such as patches and transversal cracks (Figure 4a and 5a), a field study was conducted in the sites where the problems were identified. The field study was completed approximately one month after the image acquisition flight; therefore, the sites had not undergone any significant changes.

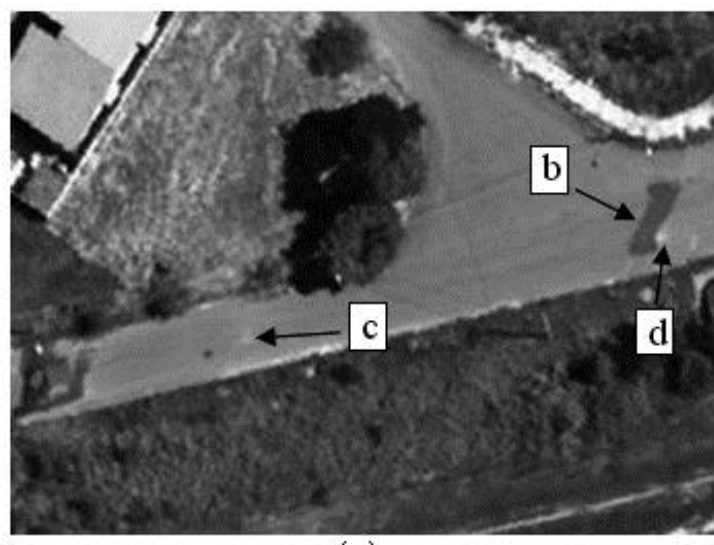

(a)

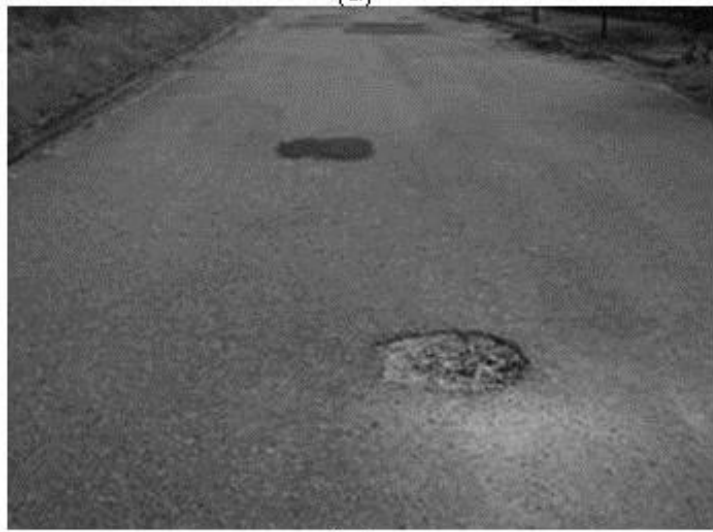

(c)

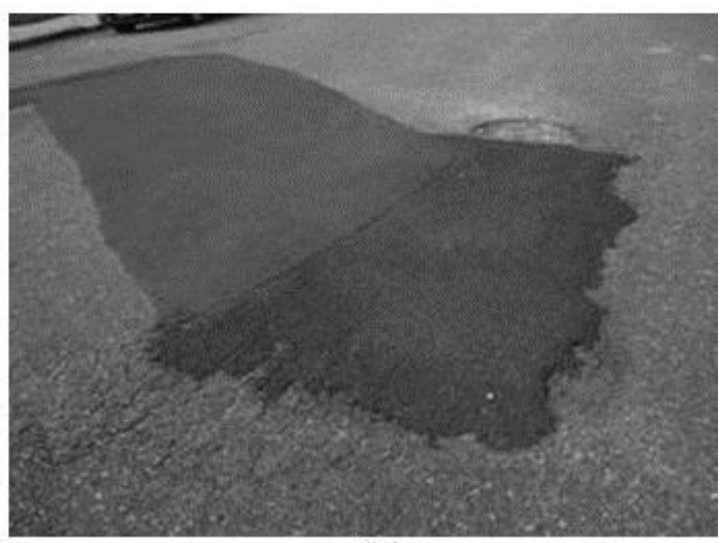

(b)

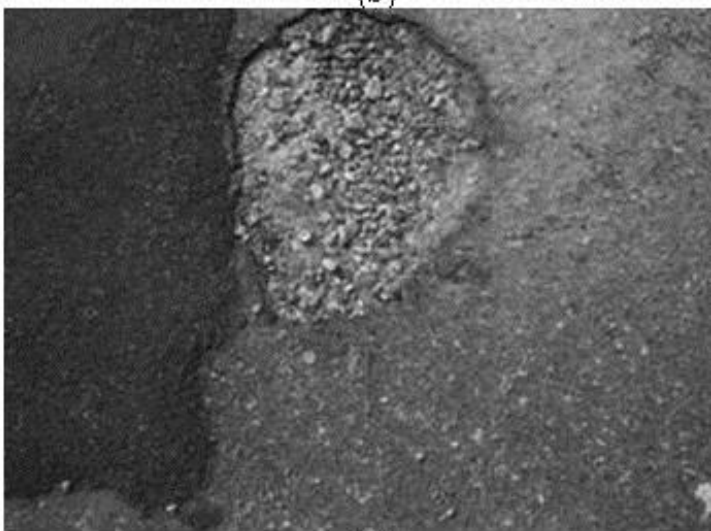

(d)

Figure 4 - (a) AOI-02 and the image collection points; (b), (c) and (d) are images from the field. 


\section{Results}

Before the field survey campaign, the potholes shown in Figure $4 \mathrm{c}$ had not been detected in the images. From the data collected in the field, it was then possible to visually locate the occurrences of the potholes found in the asphalt in the images. These potholes were approximately $50 \mathrm{~cm}$ in diameter. In the image with the better spatial resolution $(25 \mathrm{~cm})$, such a hole is equivalent to approximately 4 pixels, causing their detection by the classification algorithms to be practically impossible.

A set of long, transversal cracks was identified in the images during the preliminary visual analysis in laboratory, as shown in Figure 5a. However, during the field survey, the majority of these transversal long cracks were found to have been sealed with a black material (Figures $5 \mathrm{~b}$ and $5 \mathrm{c}$ ). This sealant material increased the contrast and thus the apparent area of the cracks, causing them to be highlighted in the captured images.

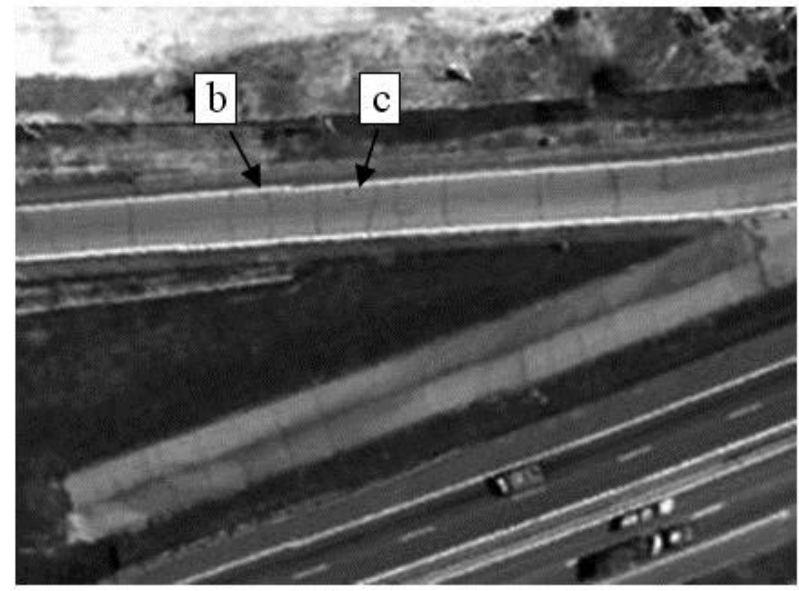

(a)

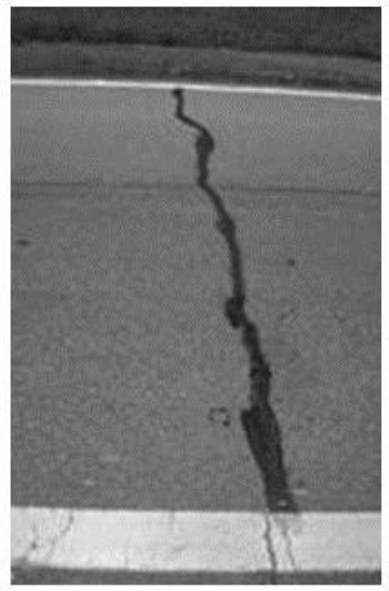

(b)

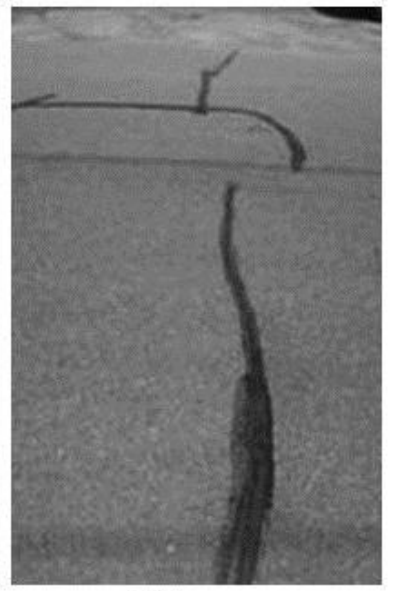

(c)

Figure 5 - (a) Image collection points; (b) and (c) are field research images.

Table 2 summarizes the final results of the asphalt detection process for the studied AOIs. Column (1) is the accuracy after the pixel-by-pixel classification using SAM, and column (16) is the final accuracy of the image after applying the spatial filters and the object-based classification. 


\section{Table 2 - Evaluation of asphalt pavement detection by applying spatial filters and object-based classification to AOIs.}

\begin{tabular}{|c|c|c|c|c|}
\hline Area & Accuracy 1 & Accuracy 16 & Difference & Percentage $\%$ \\
\hline AOI 01 & 91,22 & 93,06 & 1,84 & 2,0 \\
\hline AOI 02 & 95,03 & 94,94 & $-0,09$ & $-0,1$ \\
\hline AOI 03 & 86,83 & 87,84 & 1,01 & 1,2 \\
\hline AOI 06 & 91,98 & 93,93 & 1,95 & 2,1 \\
\hline AOI 08 & 87,70 & 90,13 & 2,43 & 2,8 \\
\hline
\end{tabular}

Patches were the defects with the greatest number of occurrences in the available images and had the highest visibility due to the size of these objects versus the resolution of the images. However, the Patch class performed poorly as a classifier for detecting asphalt patches in the images. Table 3 shows the results of the classification for the four areas of interest and also for the complete image 03. The average error rate for the Commission of an error was 55.5\%, and the average rate for the Omission of an error was 54\%. The effectiveness of this classification methodology was assessed by visually comparing the classified image with the original image.

In the absence of other images with better spatial resolutions and because of the greater availability of information concerning and samples of other types of cracks, the available images were processed with the aim to improve this classification methodology and our understanding of the behavior of the objects that comprise this Crack class. As targets smaller than the spatial resolution of the images, cracks behave differently than the other classification objects, even when considering the cracks that have been widened by the use of the sealant.

Table 4 shows the results of the crack classification in each image for both segments. These were not surveyed due to the lack of an automated method for the verification of the commission and omission of classification errors. However, the qualitative results of the classification of the cracks were worse than those of the classification of the patches. 
Table 3 - Results of the object-based classification method for the identification of patches

\begin{tabular}{|c|c|c|r|r|r|r|r|c|}
\hline \multirow{2}{*}{ AOI } & \multicolumn{2}{|c|}{ \# Objects } & \multicolumn{2}{|c|}{ Area $\left(\mathrm{m}^{2}\right)$} & \% Obj. & \%Area & Commission & Omission \\
\cline { 2 - 5 } & Patches & Asphalt & Patches & Asphalt & & & & \\
\hline AOI 01 & 102 & 2.817 & $1.163,56$ & $60.267,31$ & $3,6 \%$ & $1,9 \%$ & $49,0 \%$ & $44,7 \%$ \\
\hline AOI 02 & 20 & 727 & 209,25 & $13.946,50$ & $2,8 \%$ & $1,5 \%$ & $55,0 \%$ & $47,1 \%$ \\
\hline AOI 03 & 12 & 906 & 97,40 & $22.034,00$ & $1,3 \%$ & $0,4 \%$ & $33,3 \%$ & $52,9 \%$ \\
\hline AOI 04 & 13 & 928 & 103,31 & $20,991,81$ & $1,4 \%$ & $0,5 \%$ & $84,6 \%$ & $71,4 \%$ \\
\hline
\end{tabular}

Table 4 - Results of the object-based classification method for the identification of long cracks in the AOIs

\begin{tabular}{|c|c|c|r|r|r|l|l|l|l|}
\hline \multirow{2}{*}{ AOI } & \multicolumn{2}{|c|}{ \# Objects } & \multicolumn{2}{|c|}{ Area $\left(\mathrm{m}^{2}\right)$} & \multirow{2}{*}{$\%$ Obj. } & \% Area & \multicolumn{3}{|c|}{ Segmentation parameters } \\
\cline { 2 - 7 } & Cracks & Asphalt & Cracks & Asphalt & & & Scale & Shape & Compact. \\
\hline AOI 01 & 264 & 46.159 & 352,44 & $61.038,31$ & $0,6 \%$ & $0,6 \%$ & 20 & 0,7 & 0,9 \\
\hline AOI 01 & 109 & 20.785 & 136,44 & $61.254,81$ & $0,5 \%$ & $0,2 \%$ & 50 & 0,1 & 0,9 \\
\hline AOI 02 & 99 & 11.953 & 126,81 & $14.019,19$ & $0,8 \%$ & $0,9 \%$ & 20 & 0,7 & 0,9 \\
\hline AOI 02 & 53 & 5.373 & 66,70 & $14.079,34$ & $1,0 \%$ & $0,5 \%$ & 50 & 0,1 & 0,9 \\
\hline AOI 03 & 129 & 14.989 & 175,06 & $21.948,75$ & $0,9 \%$ & $0,8 \%$ & 20 & 0,7 & 0,9 \\
\hline AOI 03 & 54 & 6.405 & 70,50 & 22.053 .38 & $0,8 \%$ & $0,3 \%$ & 50 & 0,1 & 0,9 \\
\hline AOI 04 & 117 & 18.470 & 146,88 & $20.945,81$ & $0,6 \%$ & $0,7 \%$ & 20 & 0,7 & 0,9 \\
\hline AOI 04 & 47 & 7.600 & 59,44 & $21.032,85$ & $0,6 \%$ & $0,3 \%$ & 50 & 0,1 & 0,9 \\
\hline
\end{tabular}

Table 5 - Calculations of the ISI' and the GSI' values from the images

\begin{tabular}{|c|c|c|c|c|c|c|c|c|c|c|}
\hline AOI & $\begin{array}{c}\text { Patches } \\
\text { index }\end{array}$ & $\begin{array}{c}\text { Cracks } \\
\text { index }\end{array}$ & $\begin{array}{c}\text { Pothole } \\
\text { index }\end{array}$ & $\begin{array}{c}\text { Patches } \\
\text { freq. }\end{array}$ & $\begin{array}{c}\text { Cracks } \\
\text { freq. }\end{array}$ & $\begin{array}{c}\text { Pothole } \\
\text { freq. }\end{array}$ & $\begin{array}{c}\text { Patches } \\
\text { ISI }\end{array}$ & $\begin{array}{c}\text { Cracks } \\
\text { ISI' }\end{array}$ & $\begin{array}{c}\text { Pothole } \\
\text { ISI' }\end{array}$ & GSI' \\
\hline AOI 01 & 0,019 & 0,006 & 0 & 0,6 & 0,2 & 1 & 0,012 & 0,001 & 0,000 & 0,013 \\
\hline AOI 02 & 0,015 & 0,009 & 0 & 0,6 & 0,2 & 1 & 0,009 & 0,002 & 0,000 & 0,011 \\
\hline AOI 03 & 0,004 & 0,008 & 0 & 0,6 & 0,2 & 1 & 0,003 & 0,002 & 0,000 & 0,004 \\
\hline AOI 04 & 0,005 & 0,007 & 0 & 0,6 & 0,2 & 1 & 0,003 & 0,001 & 0,000 & 0,004 \\
\hline
\end{tabular}

Table 6 - Calculations of the EGSI' values from the images

\begin{tabular}{|c|c|c|c|c|c|c|c|}
\hline AOI & $\begin{array}{c}\text { Patches } \\
\text { index }\end{array}$ & $\begin{array}{c}\text { Cracks } \\
\text { index }\end{array}$ & $\begin{array}{c}\text { Pothole } \\
\text { index }\end{array}$ & $\begin{array}{c}\text { Patches } \\
\text { Ppr }\end{array}$ & $\begin{array}{c}\text { Cracks } \\
\text { Pt }\end{array}$ & $\begin{array}{c}\text { Pothole } \\
\text { Ppr }\end{array}$ & EGSI' \\
\hline AOI 01 & 0,019 & 0,006 & 0 & 0,7 & 0,3 & 0,7 & 0,015 \\
\hline AOI 02 & 0,015 & 0,009 & 0 & 0,7 & 0,3 & 0,7 & 0,013 \\
\hline AOI 03 & 0,004 & 0,008 & 0 & 0,7 & 0,3 & 0,7 & 0,005 \\
\hline AOI 04 & 0,005 & 0,007 & 0 & 0,7 & 0,3 & 0,7 & 0,006 \\
\hline
\end{tabular}

The last step in processing the Classification of the Asphalt Defects is the generation of index values for the defects found in the images and consequently the generation of the Global 
Severity Index for the image (GSI') or the Expedite Global Severity Index for the image (EGSI'). Tables 5 and 6 were constructed by adopting the weighting factors described in the DNIT standards for the GSI and the EGSI.

\section{Discussion}

The attainment of images with spectral and spatial characteristics sufficient for the development of the research on asphalt conditions will always be a challenge to be overcome. The best set of images collected, containing significant asphalt samples and meeting the minimal spatial and spectral resolution requirements, was obtained from the Sorocaba, São Paulo - SP region, images collected in February 2010. The images from the acquisition flight provided an opportunity to assess the methodology for monitoring highway pavement surfaces, but it was not possible to determine a region where there was a great enough number of defects on the asphalt surface.

The Sorocaba region is politically and economically distinct from the other regions of Brazil, which results in well-maintained highways, access roads, and streets in the region relative to the national average situation.

The use of spatial filter, such as Clump, Sieve, and Average, after the initial SAM classification resulted in advantages and disadvantages for the final study results. The principal advantage was the attenuation of the effect of electronic noise on the classification of defects, and the filters helped to improve the final result. Table 7 shows the general accuracy of the classification system before and after the application of the filters and the percentage of the total image area occupied by electronic noise. The performance of the filters is directly correlated with the amount of area that contains elevated rates of noise. The performance of the filters also depends on other factors, such as whether the area contains more urban or rural area. 
Table 7 - Comparison of the general accuracy of the classification of pavement defects in the areas of interest before and after the application of the spatial filters

\begin{tabular}{|c|c|c|c|c|}
\hline AOI & Accuracy after SAM & Accuracy after spatial filter & Difference & $\%$ noise in AOI \\
\hline AOI 01 & 91,22 & 92,51 & $1,4 \%$ & $31,0 \%$ \\
\hline AOI 02 & 95,03 & 94,92 & $-0,1 \%$ & $0,0 \%$ \\
\hline AOI 03 & 86,83 & 87,40 & $0,7 \%$ & $18,0 \%$ \\
\hline AOI 06 & 91,98 & 93,42 & $1,6 \%$ & $95,0 \%$ \\
\hline AOI 08 & 87,70 & 88,07 & $0,4 \%$ & $40,0 \%$ \\
\hline
\end{tabular}

The accuracy values for the results obtained from the first stage of the methodology (approximately 90\%) are high for automatic classifier results, which demonstrates the excellent performance of the asphalt detection stage using the presented methodology to process the spectral images.

Segmentation is the basis for the object-oriented classification. All object statistics are calculated from the results of segmentation. Therefore, this step plays a crucial role in determining the results and final quality of this object-based classification system.

Regarding the segmentation process, there is an inverse relationship between the spatial resolution, the spectral resolution, the scaling parameters, the form and the compactness of an object with the dimension and form of the object under analysis, or moreover, with the attributes of the analyzed object classes. The segmentation process is dependent on the classification scheme for the study objects and the images used.

The poor performance in terms of the classification of the patches, in this case, may have been associated with the large variability in forms where the patches occurred. Because the algorithm has been trained on sample objects that were selected to represent patches, the final result of the classification is very dependent on the samples selected. When the number of chosen samples is large, the confidence intervals of the relevancy functions of the patch class attributes also increases, diminishing the power of the classifier for patch discrimination. Thus, as constructed, the patch class attribute structure does not generate a strong discriminatory power. The strategy of having only one class to represent the patches does not yield an acceptable performance. The construction of patch subclasses that form a class hierarchy should be investigated; each of the subclasses could be configured for a specific 
type of patch and the sum of the results of all of these subclasses would compose the general patch index for the image under analysis.

For the case of classifying the crack-type defects, the segmentation of the images had a significant influence over the observed results. The relationship of the dimensions of the crack relative to the spatial resolution of the images is the limiting factor for obtaining a consistent classification of cracks in objects throughout an entire image and in other similar images. "The basic rule is that the scale of objects in the image to be detected must be significantly bigger than the scale of the image noise in relation to the texture. This guarantees that the subsequent processing of the object oriented image is based on objects from significant images" (Blaschke et al., 2000).

Even without an appropriate segmentation process for the classification of objects, similar to the patches, the Long Crack class could be reconstructed in the form of a subclass hierarchy of crack types; each subclass can represent a specific type of crack that is observed in the images. The sum of all the subclasses would represent the Crack class and would compose the crack index for the image under analysis. The results presented in Table 4 are not representative of the amount of cracks found in the analyzed images. They serve to demonstrate that it is not possible to systematically quantify the number of cracks and their respective areas in images of this spatial resolution.

\section{Conclusion}

The paper presents a new methodology for the identification of asphalted pavement surfaces condition and the classification of the main types of asphalt defects using hyperspectral images from airborne digital sensors.

For the second phase of this classification methodology, spatial resolution played a limited role in impacting the type of analysis intended with this research. Although the images possessed a high spatial resolution by the current standards of remote sensing, it was not possible to classify and segment the images in a systematic manner. The segmentation process was conducted at very close to the pixel level, and the objects resulting from this segmentation process did not display any sort of systematic behavior. 
Even without possessing a correct survey of the quantity of asphalt defects contained in the images, it was possible to demonstrate that the proposed methodology and the available tools allowed for the generation of indexes of defect occurrences from the images, accounting for the area of objects in the images that represent asphalt defects relative to the total area of asphalt contained in the images.

Independent of the results obtained from the set of analyzed images, the principal aim of the study is the development of a new methodology that uses the best existing image classification techniques, mixing the pixel-to-pixel classification technique with the objectbased classification technique for identification of asphalted pavement surfaces condition and the classification of the main types of asphalt defects.

New remote sensing platforms and sensors are producing high quality images, frequently, with increasingly higher spatial and spectral resolutions. The tendency of technological evolution points to a near future in which we will have images with better resolutions and thus, a greater discriminatory power than we have today.

Following this direction, the preparation of technology and processing methodologies, including the treatment and classification of objects in images, that are capable of analyzing the remote sensing images to be acquired in the future is a challenge that can be addressed today.

In summary, by using high spatial resolution images, even at the expense of spectral resolution, it is possible to calculate an asphalt quality index from the remote sensing images. The methodology presented, together with new survey systems (like hyperspectral sensors carried by drones), will permit, in the near future, the development of powerful tools for use in the planning and monitoring of the condition of pavement surfaces and for assessing the workmanship of the agencies that manage and administer Brazilian highways. 


\section{Acknowledgements}

The authors express their sincere thanks the Department of Transport Engineering of the Polytechnic School of the University of São Paulo (EPUSP), thank you for the opportunity and your support of this research. To the ATECH Critical Technologies Foundation, thank you for providing the images. To the National Research Council - CNPq, thank you for the funds for supporting the researchers.

\section{References}

Agência Nacional de Transportes Terrestres - ANTT (2008) AETT - Anuário Estatístico dos Transportes Terrestres. Available at www.antt.gov.br.

Atech Critical Technologies Application Foundation - ATECH (2010) CASI 1500 sensor imaging of the region south of the city of Sorocaba, SP, Brazil.

Bernucci, L. B., Mota, L. M. G., Cerati, J. A. P. and Soares, J. B. (2008) Asphalt Pavement: Basic formation for Engineers. Rio de Janeiro: Abeda.

Blaschke, T, Lang, S., Lorup, E, Strobl, J. and Zeil, P. (2000) Object-oriented image processing in an integrated GIS/remote sensing environment and perspectives for environmental applications. In: Cremers, A.; Gerve, K. (eds.) Environmental Information for Planning, Politics and the Public. Metropolis-Verlag, Marburg, vol. 2, pp. 555-570.

Blaschke, T. and Kux, H. (2005) Remote sensing and advanced SIG: new sensory systems innovative methods. São Paulo: Office of Texts.

Blaschke, T., Glasser, C. and Lang, S. (2005) Processing of Images in an Integrated SIG Environment/ Remote Sensing-Tendencies and Consequences.

Departamento Nacional de Infraestrutura de Transportes - DNIT NORMA DNIT 005/2003 - TER (2003) Defeitos nos pavimentos flexíveis e semi-rígidos - Terminologia, DNIT: Brasília, 2003. $12 \mathrm{p}$.

Departamento Nacional de Infraestrutura de Transportes - DNIT NORMA DNIT 006/2003 - PRO (2003) Avaliação objetiva da superfície de pavimentos flexíveis e semi-rígidos - Procedimento, DNIT: Brasília, 2003. 10p.

Departamento Nacional de Infraestrutura de Transportes - DNIT NORMA DNIT 008/2003 - PRO (2003) Levantamento para avaliação da condição de superfície de subtrecho homogêneo de rodovias de pavimentos flexíveis e semi-rígidos para gerência de pavimentos e estudos e projetos Procedimento, DNIT: Brasília, 2003. 11p.

Ferreira, E. R. and Vieira, C. A. O. (2009a) Utilização de imagens do sensoriamento remoto para detectar defeitos nas superfícies de pavimentos asfálticos. Anais XIV Simpósio Brasileiro de Sensoriamento Remoto, Natal, Brasil, INPE, pp. 951-958.

Ferreira, E. R. and Vieira, C. A. O. (2009b) Análise de curvas espectrais de 350 a $2500 \mathrm{~nm}$ para a discriminação de padrões de pavimentos asfálticos. Anais XIV Simpósio Brasileiro de Sensoriamento Remoto, Natal, Brasil, INPE, pp. 1079-1086. 
Herold, M. and Roberts, D. (2005) Spectral characteristics of asphalt road aging and deterioration: implications for remote-sensing applications. Applied Optics, vol. 44, n. 20.

Herold, M., Roberts, D. D., Noronha, V. and Smadi, O. (2008) Imaging spectrometry and asphalt road surveys. Transportation Research Part C, vol. 16, pp. 153-166.

Nóbrega, R.A., Ohara, C. G. and Quintanilha, J. A. (2008) An object-based approach to mine roads over informal settlements in São Paulo city. In: Blaschke, T., Lang, S., Hay, G. (eds.) Object based image analysis. Berlin: Springer, 2008, vol. 1, pp. 595-613.

Proto, M., Bavusi, M., Bernini , R., Bigagli,L., Bost, M.,. Bourquin, F., Cottineau, L-M., Cuomo , V., Mauro Dolce, P. D., Dumoulin, J., Eppelbaum ,L., Fornaro, G., Gustafsson, M., Hugenschmidt. J., Kaspersen, P., Kim, H., Lapenna, V., Leggio, M., Loperte, A., Mazzetti, P., Moroni, C., Nativi, S., Nordebo, S., Pacini, F., Palombo, A., Pascucci, S., Perrone, A., Pignatti. S., Ponzo, F. C., Rizzo, E., Soldovieri, F. and Taillade, F. (2010) Transport Infrastructure Surveillance and Monitoring by Electromagnetic Sensing: The ISTIMES Project. Sensors, vol. 10, n. 12, pp. 10620-1063.

Resende, M. R., Bernucci, L. L. B. e Quintanilha, J. A. (2012) Classificação híbrida: pixel a pixel e baseada em objetos para o monitoramento da condição da superfície dos pavimentos rodoviários. Boletim de Ciências Geodésicas, vol. 18, n. 3, pp. 397-420.

Resende, M. R., Jorge, S. C. H., Longhitano, G. A. and Quintanilha, J. A. (2008) Use of hyperspectral and high spatial resolution image data in an asphalted urban road extraction. IEEE International Geoscience \& Remote Sensing Symposium - IGARSS2008, Boston, USA.

Rodrigues, L. M., Resende, M. R. e Timoszczuk, A. P. (2007) Sistema de imageamento hiperespectral de alta resolução embarcado em plataforma aérea de baixo custo. XIII Simpósio Brasileiro de Sensoriamento Remoto - SBSR, Florianópolis.

Wang, K. C. P. and Smadi, O. (2011) Automated imaging technologies for pavement distress surveys, Transportation Research Circular E-C156.

Weng, Q. (2012) Remote sensing of impervious surfaces in the urban areas: Requirements, methods, and trends. Remote Sensing of Environment, vol. 117, n. 15, pp. 34-49. 